\title{
Performance Evaluation of an Active PCM Thermal Energy Storage System for Space Cooling in Residential Buildings
}

\author{
Sandris RUCEVSKIS ${ }^{1 *}$, Pavel AKISHIN ${ }^{2}$, Aleksandrs KORJAKINS ${ }^{3}$ \\ ${ }^{1-3}$ Institute of Materials and Structures, Riga Technical University, \\ Kipsalas iela 6A, Riga, LV-1048, Latvia
}

\begin{abstract}
This paper presents a numerical simulation-based study that evaluates the potential of an active phase change material (PCM) incorporated thermal energy storage (TES) system for space cooling in residential buildings. In the proposed concept, TES system is composed of stand-alone PCM storage units which are installed between the concrete ceiling slab and the ceiling finishing layer. Active control of the thermal energy storage is achieved by night cooling of a phase change material by means of cold water flowing within a capillary pipe system. Effectiveness of the system under the typical summer conditions of the Baltic States is analysed by using computational fluid dynamics (CFD) software Ansys Fluent. Results showed that installation of the active TES system has a positive effect on thermal comfort, reducing the average indoor air temperature by $6.8^{\circ} \mathrm{C}$. The outcome of this investigation would be helpful in selecting the key characteristics of the system in order to achieve the optimum performance of an active TES system for space cooling of buildings in similar climates.
\end{abstract}

Keywords - Dynamic thermal simulations; nearly zero energy buildings; phase change materials (PCM); space cooling; thermal energy storage (TES)

\section{INTRODUCTION}

According to the data form the European Commission, building sector is the dominant energy consumer in the EU and accounts for approximately $40 \%$ of total energy consumption and over $36 \%$ of greenhouse gas emissions in the EU [1]. Therefore, the EU has introduced a number of legislative instruments promoting the improvement of the energy performance of buildings - the 2010 Energy Performance of Buildings Directive [2] and the 2012 Energy Efficiency Directive [3]. The Directives mandate to minimize the energy use in buildings by renovating old buildings and constructing new buildings with nearly zero energy consumption. These requirements drive engineers and scientists to search for new solutions and building concepts [4]-[6] that contribute to achieving the mentioned energy goals.

Conventional heating, ventilating, and air conditioning (HVAC) systems are responsible for most of the energy use in buildings as well as for associated greenhouse gas emissions [7]. Hence there is a demand for alternative energy technologies such as thermal energy storage (TES) systems that can reduce the energy consumption and improve the energy conservation in buildings. The recent developments in TES systems show that latent heat thermal storage systems with the application of phase change materials (PCMs) have received considerable attention due to their ability to provide high energy-storage density and their ability to store thermal energy at

\footnotetext{
* Corresponding author.

E-mail address: sandris.rucevskis@rtu.lv 
relatively constant temperatures [8]-[11]. While energy storage capabilities of traditional building materials are restricted to sensible heat, the PCM ability to store energy is defined by latent heat of fusion. PCM absorb or release the energy equivalent to their latent heat during the phase change process thus providing a large heat capacity over a limited temperature range [9].

TES systems with application of PCM for buildings can generally be divided into three categories: passive, active and free cooling systems for heating and cooling. In passive application systems, PCMs are incorporated into a building envelope to increase thermal mass, and the TES system operates without the external supply of energy. This way phase change material will absorb or release energy if the adjacent air or surface temperature is above or below the melting point. Typically, in passive applications PCM melts during the daytime thus absorbing the heat and solidifies during the night by dissipating the stored energy. Many studies [12]-[17] have reported that incorporating PCMs in passive applications for cooling and heating can improve indoor thermal comfort and reduce the building energy consumption; however, the energy savings and amount of temperature reduction varies significantly and largely depends on the thermo physical properties of PCM, internal gains and local climatic conditions.

Since PCMs are a form of thermal energy storage that requires dissipation of the stored heat to return to a solid state in order to begin a melt-freeze cycle again, the major drawback of passive cooling applications is that PCM may not solidify completely at the end of night cooling. Due to that PCM mainly interacts with indoor air which temperature most part of a summer night is higher than temperature of the phase change, night cooling duration may not be sufficient to completely solidify the PCM. To overcome this problem during the last two decades free cooling and active application methods have been investigated extensively by many researchers.

The free cooling is a technique based on natural night time ventilation to dissipate the PCMs stored energy and its working principle is based on two operation modes. The first mode is similar to the passive application method - during the day-time indoor air circulates through the PCM storage unit, where PCM melts by absorbing the heat from the indoor air thus reducing the room air temperature. In the second mode, during the night-time when the outdoor temperature is lower than the indoor temperature, cold ambient air is circulated through the PCM storage unit releasing the stored heat and PCM starts to solidify. Many studies [18]-[22] have shown that free cooling TES systems are a promising technique, however, their application strongly depends on the local diurnal temperature range - it has to be between $12{ }^{\circ} \mathrm{C}$ and $15^{\circ} \mathrm{C}$ in order for a system to be effective [10].

Contrary to the free cooling, active TES systems commonly use fans and pumps to transfer energy to air or water, which serve as the working fluids to move thermal energy of PCMs. In active application systems, the storage capacity of PCMs is typically integrated into HVAC systems such as solar heat pumps, air-conditioning units, floor heating and thermally active ceiling panels [23]-[26]. Detailed analysis on the latest developments in the fields of the active application and free cooling systems with PCM can be found in extensive reviews [27]-[29]. Reviews show that PCM applications in both the active and free cooling systems are effective and technically feasible; however, more research is needed to convey the concept from the theoretical and experimental stage to the real implementation phase [10].

There are various methods to incorporate PCMs into building envelope. PCMs can be integrated as separate components into building envelope (encapsulation) or integrated directly (immersion and impregnation) into conventional building materials. Typical applications of the direct integration into building materials include PCM-impregnated wallboard, concrete, floors, ceiling and roofing materials [30]. Encapsulation, on the other hand, involves containing the PCM with another material. Two encapsulation techniques can be defined: the micro- and macro-encapsulation. Micro-encapsulated PCMs are typically contained by microscopic polymeric capsules which then are incorporated into various 
building materials [30]. The macro-encapsulation is the technique in which PCMs are contained in a wide range of containers such as tubes, spheres and panels that interact with other building materials through conduction and convection.

Although PCM can be integrated into any component of the building envelope, wallboard applications have been the most common approach used in passive application methods. Contrary, in active application methods PCMs are widely integrated into the building ceiling as it is the most exposed surface of the interior space, thus subjected to the highest indoor temperatures. In most of the active application methods PCM storage units are used in connection to air-based systems, however, there are several studies investigating the waterbased systems. These systems use water as a heat carrier to satisfy the sensible cooling loads. Koschenz and Lehman [25] described the development of a thermally activated ceiling panel for incorporation in lightweight and retrofitted buildings. Active control of the thermal storage is achieved by integrating a water capillary tube system in the micro-encapsulated phase change material/gypsum composite. It was demonstrated that a $5 \mathrm{~cm}$ layer of PCM suffice to maintain a comfortable room temperature in standard office buildings. Tzivanidis et al. [26] conducted a parametric analysis for ceiling cooling system with PCM embedded piping. Active regeneration of the PCM was realized via cold water flowing. Investigation showed that the selection of proper values for the system's main parameters such as pipe spacing, PCM layer thickness, night cooling duration and cooling water inlet temperature is paramount in order to achieve the optimum performance of the system.

In this paper, a new concept for an active PCM thermal energy storage system is described. TES system composed of stand-alone PCM storage units is proposed for space cooling in a multi-storey nearly zero-energy residential buildings. The system is integrated into the building interior between the concrete ceiling slab and the ceiling finishing layer. Active control of the PCM thermal storage is achieved by night cooling of a phase change material by means of cold water flowing within a capillary pipe system incorporated in the storage unit. The main focus of this study is to investigate numerically the thermal response of the proposed active TES system under summer climatic conditions of the Baltic States. For the comparison purposes performance analysis of the passive application (without the night cold water cooling of the phase change material) of the proposed PCM storage unit is also conducted in this study.

\section{Concept for An ACtive Thermal EnERgy Storage SySTEM}

Considering the latest developments in the field, the aim of this study was to design an active TES system with the application of phase change materials for space cooling in nearly zero-energy residential buildings. The main requirements for the TES system was to achieve thermal storage capacity approximately equal to the heat gains within the space during the daily cycle and to be suitable for local installation in the building interior while occupying minimum space. In the design process three main considerations were defined: PCM integration method, PCM storage location in the building interior, PCM cooling method.

The above considerations prompted a design of a TES system of stand-alone PCM storage units located between the concrete ceiling slab and the ceiling finishing layer. The macro-encapsulation technique is adopted for the storage unit as a steel tray serves as a container for phase change material. The PCM in the storage unit melts during the daytime upon exposure to the internal thermal loads and solidifies overnight by means of cold water flowing within a capillary pipe system incorporated in the storage unit. Each unit is separately connected to one cooling water inlet and one outlet in order to achieve maximum night cooling effectiveness. The overall concept of the PCM thermal energy storage unit is given 
in Fig. 1. The main advantage of this concept is the simple integration of the system into the building interior compared to other TES systems as the stand-alone unit can easily be added, removed or retrofitted without affecting the building structure.

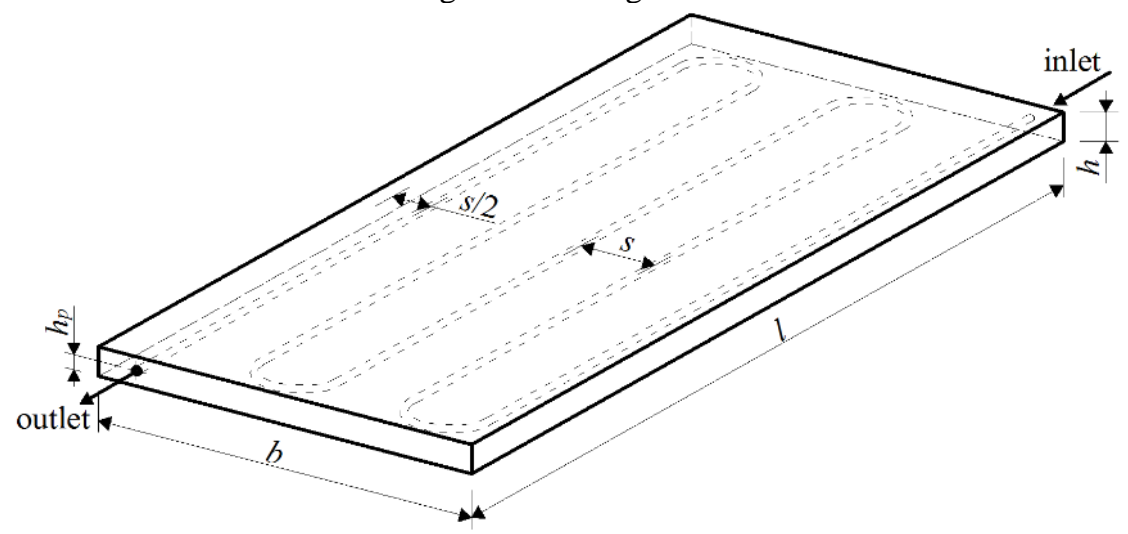

Fig. 1. Schematic representation of the PCM thermal energy storage unit.

\section{NuMerical Modelling}

The objective of the present work was to investigate numerically the performance of the proposed TES system for space cooling in residential buildings. Numerical simulations were performed to determine the required storage unit characteristics such as quantity of PCM, number of embedded pipes, the cooling water inlet temperature and night cooling duration.

In order to minimize the computational efforts, numerical simulations were carried out in two stages: 1) a two-dimensional finite element model (building model) for a room of a typical multi-storey residential house is developed and the related heat-transfer problem is solved; 2) a detailed three-dimensional numerical model (storage unit model) of the PCM thermal energy storage unit is developed and solved for the night cooling of PCM. General solution algorithm is as follows: In the first stage, a typical building thermal condition simulation for a room with the integrated PCM storage unit is carried out for a defined time period. In the next stage, simulation results of the building model are supplied into the 3D storage unit model for simulation of the night cooling of PCM. Obtained results of the night cooling are then supplied back to the building model and the room thermal condition simulation for the next time period is performed. The procedure is repeated continuously for the whole analysis period. In summary, each calculation consists of the 2D building simulation of the room thermal condition incorporating output of the night cooling simulation using the 3D storage unit model. Solving of both models is done by means of computational fluid dynamics in the Ansys Fluent software which employs the finite volume method for solving the mass, momentum and energy conservation equations.

\subsection{Building Model}

The present study is carried out in the frames of the project aiming at the development of a new concept for sustainable nearly zero-energy buildings. The proposed concept for a design of multi-storey residential building assumes that a load bearing core is made of lightweight high-performance cement composite which subsequently allows building envelope to be self-supporting and made of bio-based materials with improved hydrothermal properties. 
Thus, the object of the present case study is a living room with dimensions of $6 \times 6 \times 3 \mathrm{~m}$ located on the second floor of a multi-storey residential house designed according the proposed concept. The external walls are constructed from three layers of bio-based materials with total thickness of $0.37 \mathrm{~m} \mathrm{[31].} \mathrm{The} \mathrm{internal} \mathrm{walls} \mathrm{and} \mathrm{floors} \mathrm{are} \mathrm{made} \mathrm{of} 0.12 \mathrm{~m}$ thick high-performance cement composite [32]. Façade side contains $40 \%$ fenestration which comprises $7.2 \mathrm{~m}^{2}$. The windows feature three layers of glazing $(4 \mathrm{~mm})$ with air gap $(9 \mathrm{~mm})$ between the layers. The system of stand-alone PCM storage units is installed under the lower surface of the concrete ceiling slab. Detailed properties of all materials used in this study are listed in Table 1.

TABle 1. MATERIAl THERMAl PROPERTIES

\begin{tabular}{lllll}
\hline Domain & Material & $\begin{array}{l}\text { Density, } \\
\mathbf{k g} / \mathbf{m}^{\mathbf{3}}\end{array}$ & $\begin{array}{l}\text { Specific heat, } \\
\mathbf{J} /\left(\mathbf{k g} \cdot{ }^{\circ} \mathbf{C}\right)\end{array}$ & $\begin{array}{l}\text { Thermal conductivity, } \\
\mathbf{W} /\left(\mathbf{m} \cdot{ }^{\circ} \mathbf{C}\right)\end{array}$ \\
\hline Air & Air & $*$ & 1000 & 0.0267 \\
Inner wall and slabs & Concrete & 2322 & 850 & 1.7 \\
External wall & Outer layer $(30 \mathrm{~mm})$ & 452.2 & 1650 & 0.112 \\
& Middle layer $(290 \mathrm{~mm})$ & 210.1 & 1250 & 0.062 \\
& Inner layer $(50 \mathrm{~mm})$ & 332.5 & 1450 & 0.077 \\
Window & Glass $(4+4+4 \mathrm{~mm})$ & 2500 & 840 & 0.76 \\
& Air $(9+9 \mathrm{~mm})$ & 1.3 & 1000 & 0.0267 \\
Finishing layer of the ceiling & Lumped & 1000.8 & 840.1 & 0.7441 \\
PCM container & Gypsum & 800 & 950 & 0.15 \\
& Steel (walls) & 8030 & 502.5 & 16.27 \\
& Copper (pipes) & 8978 & 381 & 387.6 \\
& Water (heat transfer agent) & 998.2 & 4182 & 0.6 \\
\hline
\end{tabular}

*Air density is temperature dependent: $\rho=1.292-0.00466 \cdot T\left({ }^{\circ} \mathrm{C}\right)+0.00001367 \cdot T^{2}\left({ }^{\circ} \mathrm{C}\right)$

TABle 2. Thermal Properties of Phase Change MATERIAL

\begin{tabular}{llllll}
\hline Phase & Temperature, ${ }^{\circ} \mathbf{C}$ & Density, $\mathbf{k g} / \mathbf{m}^{3}$ & $\begin{array}{l}\text { Specific heat, } \\
\mathbf{J} /\left(\mathbf{k g} \cdot{ }^{\circ} \mathbf{C}\right)\end{array}$ & $\begin{array}{l}\text { Thermal } \\
\text { conductivity, } \\
\mathbf{W} /\left(\mathbf{m} \cdot{ }^{\circ} \mathbf{C}\right)\end{array}$ & $\begin{array}{l}\text { Heat storage } \\
\text { capacity, J/kg }\end{array}$ \\
\hline Solid & $<20$ & 760 & 2000 & 0.2 & - \\
$\begin{array}{l}\text { Melting/ } \\
\text { solidification }\end{array}$ & $20 \ldots 23$ & $1160-20 T\left({ }^{\circ} \mathrm{C}\right)$ & 2000 & 0.2 & 16000 \\
Liquid & $>23$ & 700 & 2000 & 0.2 & - \\
\hline
\end{tabular}

Numerical model of the room is reduced to a $2 \mathrm{D}$ problem due to negligible changes in z-direction. Accordingly, a two-dimensional finite element model is developed and the related heat-transfer problem is solved. Since the room is taken as a part of multi-storey building, only a half of the thickness $(0.06 \mathrm{~m})$ of the internal walls and floors is modelled and symmetry boundary conditions (zero heat transfer) are applied to the corresponding sides of the computational domain. Outer surface of the external wall is described as convective boundary with a convection heat transfer coefficient $h=25 \mathrm{~W} /\left(\mathrm{m}^{2} \cdot{ }^{\circ} \mathrm{C}\right)$ at the surface. Air flow inside the room due to natural convection is expected to be turbulent, and standard $k-\varepsilon$ model is used 
to describe this flow. Surface-to-Surface radiation model is used to simulate radiative heat exchange between indoor surfaces of solid domains.

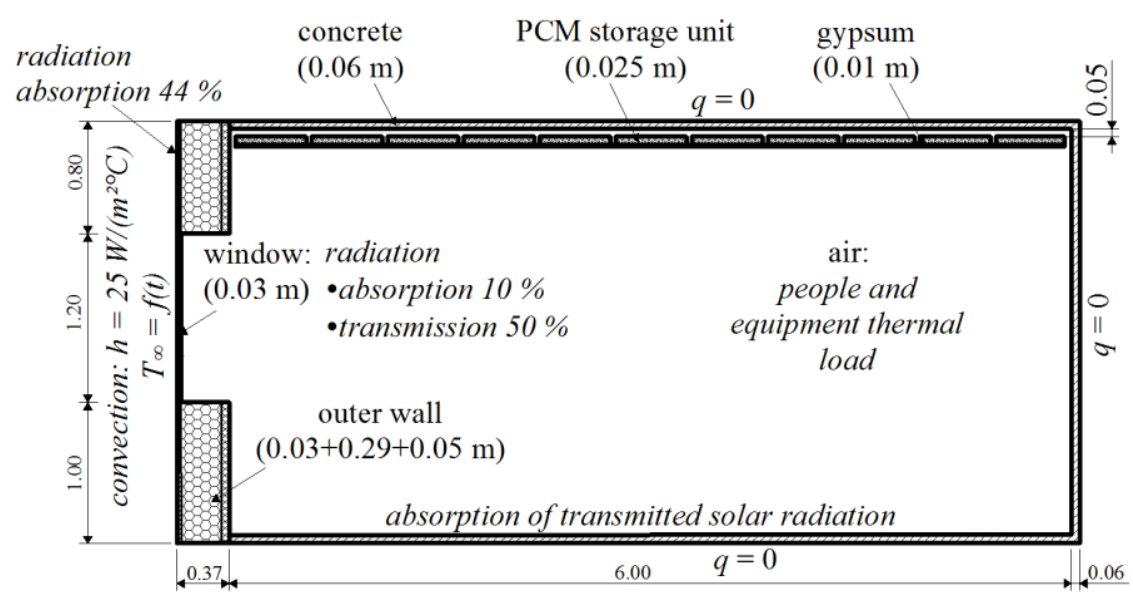

Fig. 2. Schematic representation of the 2D simulation domain.

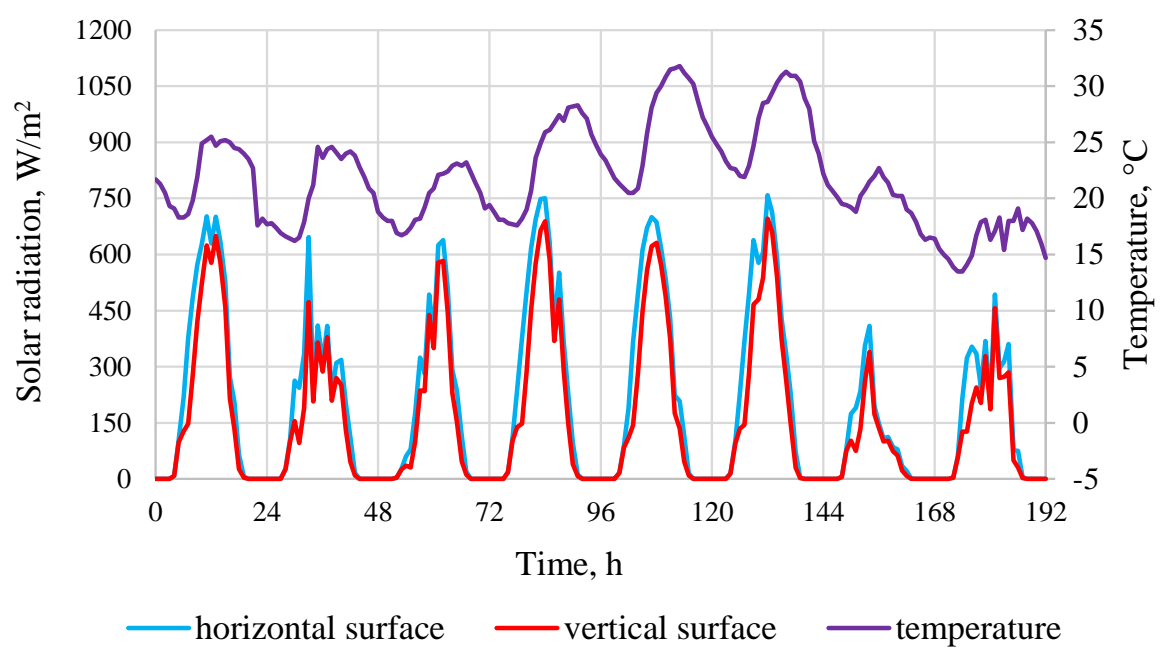

Fig. 3. Outdoor air temperature and solar radiation.

For the 2D model, TES system is assumed to be built of 11 steel containers with dimensions of $500.25 \mathrm{~mm}$ and wall thickness of $0.5 \mathrm{~mm}$. The storage unit is filled with phase change material paraffin RT22HC [33]. PCM thermal properties according to the manufacturer data are given in Table 2. The storage units are located under the concrete ceiling slab at the distance of $50 \mathrm{~mm}$ and covered by the $10 \mathrm{~mm}$ thick finishing layer (gypsum board). To enhance the heat transfer between the indoor air and the PCM, the finishing layer is closely attached to the storage unit leaving no air gap between them. Dimensions and the schematic diagram of the 2D simulation domain are depicted in Fig. 2. Night cooling of the phase change 
material is simulated by using a separate 3D PCM storage unit model and the obtained results are supplied to the building model at the defined time step.

The meteorological parameters (Fig. 3) of Riga during the period of $5^{\text {th }}$ to $12^{\text {th }}$ of August 2018 were chosen to represent the typical weather conditions of a hot summer in the Baltic States. In order to account for the hottest possible scenario, it is assumed that the fenestration façade is south oriented. Solar radiation incident on the south oriented vertical plane is recalculated according to the numerical weather forecast models available at [34]. Absorption coefficient of 0.44 for solar radiation incident to external wall surfaces is selected. The fenestration transmission coefficient of 0.6 is adopted. Solar radiation absorbed by glazing equals $10 \%$ while the indoor air and interior surfaces absorbs $50 \%$. Absorbed energy is simulated by equivalent time-depending heat sources distributed in a thin outside layer of the external wall, in a window domain and in a thin boundary layer between the indoor air and floor, respectively. Internal gains of $5 \mathrm{~W} / \mathrm{m}^{2}$ due to people, lighting and equipment are taken in to account. Indoor loads are applied as an equivalent heat source homogenously distributed in the air domain. A ventilation and infiltration rate of 1 air changes per hour $(\mathrm{ACH})$ is included in the simulation.

Characteristic size of the finite elements varies from 3 to $40 \mathrm{~mm}$ depending on the simulation domain (smaller elements are used for window, gypsum board and PCM domains, larger - for walls, concrete slabs and inner air). Total number of 4-nodal planar elements used in the building model is 21440 . Transient analysis with initial temperature of $20^{\circ} \mathrm{C}$ (equal to the solidus temperature of PCM) for all domains and constant time step size of $5 \mathrm{~s}$ is carried out for 192 h or 8 days. Selected time step provides a stable solution convergence and is based on the results of the convergence study of the inner air temperature. The developed numerical model was tested for the establishment of periodic steady state, i.e. the solution repeats itself every $24 \mathrm{~h}$ when $24 \mathrm{~h}$ meteorological data is used. Applying $0.3{ }^{\circ} \mathrm{C}$ convergence criterion, periodic steady state was reached in five $24-\mathrm{h}$ cycles.

\subsection{Storage Unit Model}

In this paper, only the most effective configuration (pipe spacing, PCM layer thickness, water inlet temperature and velocity) of the PCM storage unit for the studied room is considered. Casing made of $0.5 \mathrm{~mm}$ thick sheet steel with internal dimensions of $1000 \cdot 500 \cdot 25 \mathrm{~mm}$ serves as a container for phase change material. Solidification of PCM is achieved by cold water flowing within 13 parallel copper pipes of internal diameter of $7 \mathrm{~mm}$ and wall thickness of $0.5 \mathrm{~mm}$ which are introduced at the distance of $38.5 \mathrm{~mm}$ to each other and at the depth of $12.5 \mathrm{~mm}$ from the undersurface of the storage unit. PCM storage unit is connected to one cooling water inlet and one outlet. Cooling water flow with inlet temperature $T=15{ }^{\circ} \mathrm{C}$ and velocity $v=0.2 \mathrm{~m} / \mathrm{s}$ is considered turbulent and standard $k-\varepsilon$ model is used to describe it. Material properties used for the 3D model are given in Table 1. A fragment of 3D finite element model for the storage unit and the schematic diagram of the simulation domain are given in Fig. 4.

Characteristic size of the finite elements varies from 1 to $6 \mathrm{~mm}$ depending on the domain. Hexagonal 8-nodal elements are used for mapped mesh of water and pipe domains, tetrahedral 4-nodal and pyramidal 5-nodal elements - for free mesh of PCM domain. Total number of elements is 1283 434. Series of transient analyses with initial temperature and intensity of boundary heat flux obtained from the building model is carried out with constant time step size of $5 \mathrm{~s}$. 


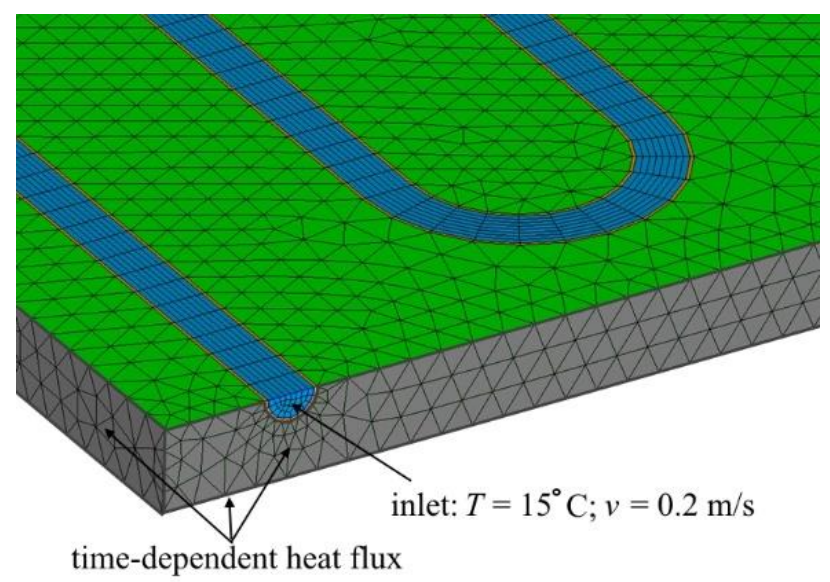

Fig. 4. Fragment of 3D finite element model.

\subsection{Governing Equations for PCM}

Two methods - the Enthalpy Method [35] and the Effective Thermal Capacity Method [25], [36], are generally employed for numerical simulation of phase change process. Since in the present study the phase change is interesting only as a macroscopic phenomenon, the latter method is selected. The selected method describes the PCM thermal capacity as a function of temperature in the phase change range. The method considers that the PCM is fully charged above the solidification temperature and fully discharged below the melting temperature. In order to mathematically describe the process inside the PCM storage unit, the following assumptions have been made:

- The PCM is homogeneous and isotropic;

- PCM properties are assumed to be constant in both solid and liquid phase except for the mass density;

- Convective flow of the PCM is accounted due to density change during melting/solidification.

The enthalpy of the PCM is computed as the sum of the sensible enthalpy, $h$, and the latent heat, $\Delta H$ :

$$
H=h+\Delta H,
$$

and

$$
h=h_{\mathrm{ref}}+\int_{T \mathrm{ref}}^{T} C_{p} d T
$$

where

$h_{\text {ref }} \quad$ Reference enthalpy;

$T_{\text {ref }} \quad$ Reference temperature;

$C_{\mathrm{p}} \quad$ Specific heat.

The latent heat content according to Ansys Fluent model is calculated in terms of the latent heat of the material, $L$, and liquid fraction, $\beta$ : 


$$
\Delta H=\beta L .
$$

The latent heat content can vary proportionally to temperature change between zero (for a solid) and $L$ (for a liquid), since it is assumed that $\beta=0$ if material temperature is lower than the solidification (solidus) temperature, $\beta=1$ if material temperature is above the melting (liquidus) temperature, and varies linearly for temperatures between solid and liquid state:

$$
\beta=\frac{T-T_{\text {solidus }}}{T_{\text {liquidus }}-T_{\text {solidus }}} .
$$

Graphical representation of the melting/solidification and heat capacity models for partial enthalpy together with experimental data for heating and cooling provided by material manufacturer are given in Fig. 5. The idealized models correspond to the Effective Thermal Capacity Method and are built according to the nominal heat storage capacity guaranteed by the manufacturer (Table 2).

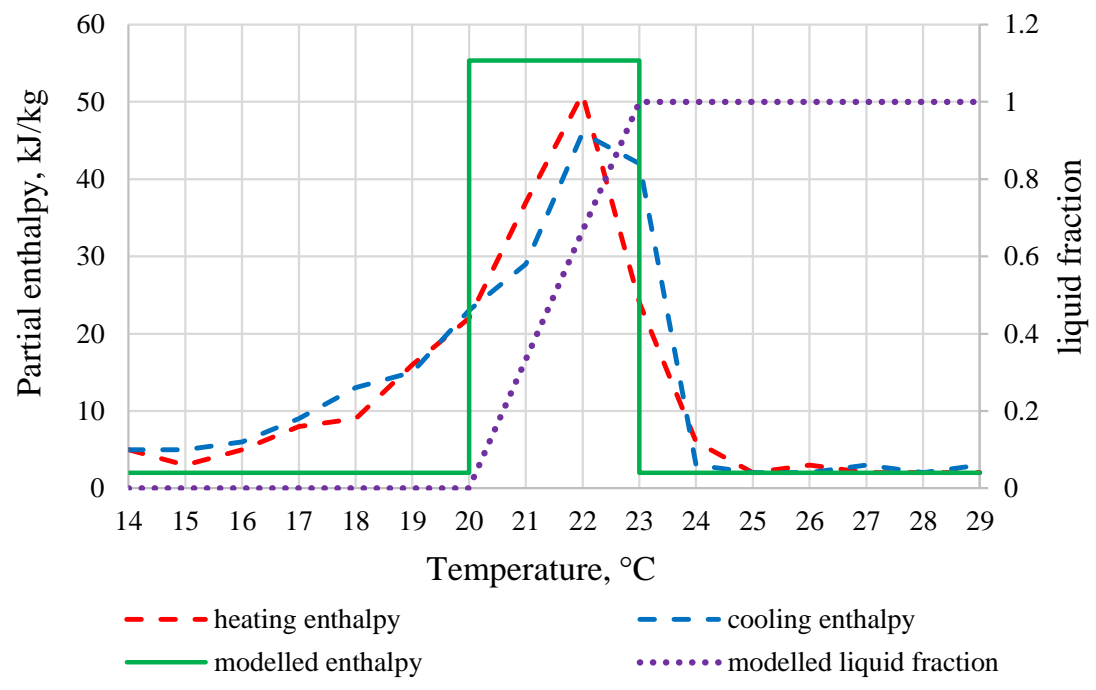

Fig. 5. Specific heat capacity and melting model of RT22HC.

\subsection{Numerical Simulation Procedure for the Active Control of the PCM Thermal Storage}

Based on the preliminary analysis, the active regeneration of the PCM begins every night at 22:00 h. For this reason, the 2D building thermal condition simulation for the room with the integrated PCM storage units is performed for each day till 23:00 h. Then obtained calculation results are transferred to the 3D model for the simulation of the night cooling. Principal characteristic linking both developed models is the phase transition state of the PCM, expressed in terms of the liquid fraction. Since CFD software Ansys Fluent does not support direct transfer of liquid fraction of the PCM between the models, it is proposed to use the average temperature of the PCM instead, which can be calculated from the average liquid fraction by using (4). Thus, the average temperature inside the PCM storage unit at 22:00 $\mathrm{h}$ is derived from (4) and together with the time-dependent heat exchange between the indoor air and the PCM storage unit for the time period between 22:00 $\mathrm{h}$ and 23:00 $\mathrm{h}$ is supplied into 
the 3D model. This information is then used to simulate the heat transfer between cold water and the PCM for this time period. In the next stage, the derived average liquid fraction of the PCM at 23:00 $\mathrm{h}$ is employed to calculate the average temperature inside the PCM storage unit by using (4), which is then supplied back to the $2 \mathrm{D}$ model for the room thermal condition simulation for the next time period $(23: 00-24: 00 \mathrm{~h})$. The routine outlined above is performed continuously using one-hour calculation step until the PCM inside the storage unit has completely solidified. This is followed again by the $2 \mathrm{D}$ building thermal condition simulation till the next night cooling of the PCM.

\section{RESUlTS AND DisCUSSION}

The objective of the present work was to investigate numerically the performance of the active PCM thermal energy storage system for space cooling in residential buildings. Nearly zero-energy requirements in northern climate demand the thermal storage and insulation properties of the building envelope to be designed in order to delay and decay the outdoor temperature and to reduce the heat loss during winter. On the other hand, well-insulated building envelope and highly glazed façade causes overheating of the building in summer time, and therefore comfortable indoor air temperature cannot be maintained without space cooling in the Baltic climate. To ensure acceptable thermal comfort the indoor air temperature should be in range between $21{ }^{\circ} \mathrm{C}$ and $28^{\circ} \mathrm{C}$. As one can see in Fig. 6, the indoor air temperature rises well above the defined comfort level without space cooling during a hot summer week in Riga. During the analysis period, the maximum indoor temperature reaches $40.9^{\circ} \mathrm{C}$ on August 10 when the highest solar radiation gains in combination with the outdoor air temperature of $30.9{ }^{\circ} \mathrm{C}$ are observed. However, it must be noted that in order to assess the performance of the TES system, the most extreme scenario is considered in this study: the glazed façade is south oriented and the fenestration transmission coefficient of 0.6 for solar radiation is assumed as there is no low-emissivity coating on the glass surface or mechanical blinds considered in the simulation.

Two types of TES systems - passive and active - for space cooling are analysed in this numerical investigation. In the passive application, the proposed TES system is used without the night cold water cooling of the phase change material. In this case, the 2D building thermal condition simulation for the room with integrated PCM storage units is performed for the whole analysis period. Obtained results (Fig. 6) show that the indoor air temperature was reduced by an average of $3.1^{\circ} \mathrm{C}$ with a maximum reduction of $4.0^{\circ} \mathrm{C}$ throughout the first 3 days due to the passive application system. However, as it was expected, PCM suffers from poor solidification rate at night, thus the full storage capacity of the phase change material is not available during the day. Although the outdoor air temperature drops below the solidification temperature $\left(23^{\circ} \mathrm{C}\right)$ of the PCM every day, the indoor air temperature never drops below the $24{ }^{\circ} \mathrm{C}$ due to well-insulated building envelope. As it is evident in Fig. 6, the indoor air temperature does not allow the PCM to solidify overnight; moreover, it keeps on melting during the night only at a slower rate. Fig. 6 shows that the PCM melts completely during the fourth day of the analysis period, nevertheless, it still provides sensible heat storage as an average reduction of $2.5^{\circ} \mathrm{C}$ in air temperature is observed during the following days.

Obtained results of the passive cooling application suggest that the additional dissipation of the PCM's stored heat is required in order to take the entire advantage of the storage capacity. Slope change of the PCM liquid fraction curve in the passive application suggests that the active regeneration of the PCM should begin at around 22:00 $\mathrm{h}$ and should be completed before 06:00 h, which corresponds to the daily solar gain cycle. Therefore, in this 
study, flow of the cooling water within a capillary pipe system is set on at 22:00 $\mathrm{h}$ and turned off when the PCM has returned to the solid state.

Results presented in Fig. 6 show that the active application of PCM can achieve significantly larger reduction of the indoor air temperature compared to the passive cooling application. This is demonstrated by an average of $6.8^{\circ} \mathrm{C}$ reduction of indoor air temperatures with a maximum reduction of $10.5^{\circ} \mathrm{C}$ in comparison to the simulation results of the building with no TES system installed. However, the maximum indoor temperature reaches $30.4{ }^{\circ} \mathrm{C}$ which is above the defined thermal comfort level of $28{ }^{\circ} \mathrm{C}$. This suggests that the latent heat storage capacity could be increased; but on the other hand, Fig. 6 shows that only $65.7 \%$ of the PCM have melted during the hottest day while on other days, liquid fraction of the PCM is as low as $24.1 \%$. Preliminary calculations proved that although the storage capacity increases by increasing thickness of the PCM layer; area of the integrated PCM or in this case the number of the storage units has a significantly larger impact on the stored heat amount. This is because low thermal conductivity of the PCM obstructs proper heat absorbing and dissipation. Taking into account the technological installation restraints, already the maximum possible number of the PCM storage units covering entire ceiling area is considered in this investigation. Therefore, for the studied room the best solution would be to additionally introduce mechanical blinds or low-emissivity coating on the glass surface to reduce the daily solar gains as they accounted for approximately $76 \%$ of total heat gains. Integration flexibility of the proposed system allows designing a custom TES system suitable for rooms with different thermal conditions. This way the entire PCM storage capacity can be used.

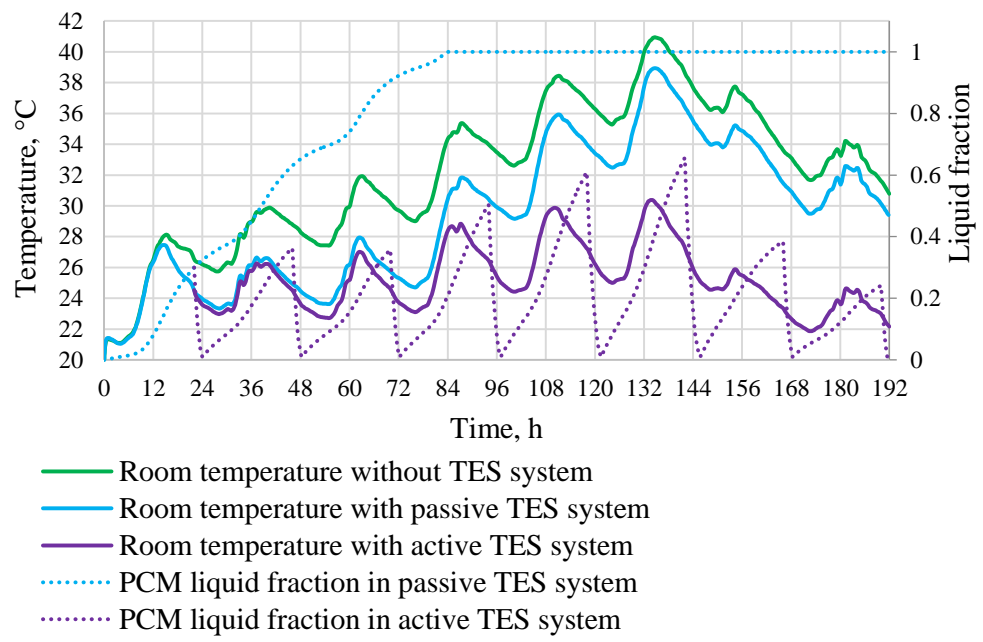

Fig. 6. Dependences of temperature and liquid fraction on time.

Illustration of the active control of the thermal storage is given in Fig. 7-10 by an example of the night cooling of the PCM on the sixth day of the analysis period. Graphical temperature distribution inside the storage unit is presented on the left while the PCM liquid fraction plot is given on the right. As shown in Fig. 7, at the beginning of the night cooling the average temperature of $21.97{ }^{\circ} \mathrm{C}$ is uniformly distributed over the whole PCM domain corresponding to the liquid fraction of $65.7 \%$ according to Eq. (4). After one hour of the night cooling the PCM temperature inside the storage unit varies from $15.16^{\circ} \mathrm{C}$ in regions around the pipes to $21.99{ }^{\circ} \mathrm{C}$ at the edges of the unit. Graphical representation of the PCM liquid fraction given 
in Fig. 8(b) shows that PCM is already in the solid state around the pipes while at the edges of the unit liquid fraction has increased from initial $65.7 \%$ to $66.5 \%$. This is because the indoor air temperature during the night is higher than the phase change temperature not allowing the storage unit walls to cool down. Nevertheless, the average liquid fraction of the PCM has decreased to $34.9 \%$ due to the cold water flow. Fig. 9 presents the results of the night cooling after 2.5-hour duration. Temperature distribution shows that PCM temperature in regions neighbouring the water inlet is approximately equal to the water temperature suggesting that PCM has solidified here while regions next to the water outlet are still in the two-phase state. Correspondingly, the average liquid fraction of the PCM has dropped down to $8.6 \%$. Fig. 10(a) depicts the temperature profile corresponding to 3 hours and 46 minutes of night cooling. It is seen that the PCM temperature inside the storage unit is mostly lower than the solidus temperature of the PCM except for the edges of the unit. Calculations showed that due to continuous heat loads owing to the indoor air temperature being above the freezing point, it would take a few more hours of the night cooling to completely solidify PCM. For this reason, the liquid fraction of $1 \%$ is adopted as a trigger value to end the night cooling.

The performance of the night cooling for the analysis period is presented in Fig. 11. It shows that night cooling duration varies from $1 \mathrm{~h} 29 \mathrm{~min}$ to $3 \mathrm{~h} 46 \mathrm{~min}$ for solidification of $24.1 \%$ and $65.7 \%$ of the liquid fraction of PCM, respectively. The solid line in the figure refers to interpolated values which are obtained by approximating the calculated values (dots) while the dashed lines are extrapolation of the approximated values. The obtained curve indicates that for the current configuration of the PCM storage unit it would take approximately 5 hours for a completely melted PCM to return to the solid state. These results suggest that for the studied room the present system is able to cool down PCM in the desired time, however, the system's main parameters could be changed to more favourable values as far as energy saving is considered. For example, night cooling duration may be increased by decreasing the number of pipes or increasing the cooling water inlet temperature. Preliminary calculations showed that water velocity has a minimal effect on the cooling power; therefore, it should be selected considering physical and technical specifications of the water pump. As expected, analysis of the effect of the pipe depth within the storage unit showed that the system performs best when pipes are embedded at the middle of the unit. In summary, this study showed that for the optimum performance of the space cooling system, a proper selection of the system's main parameters is critical.

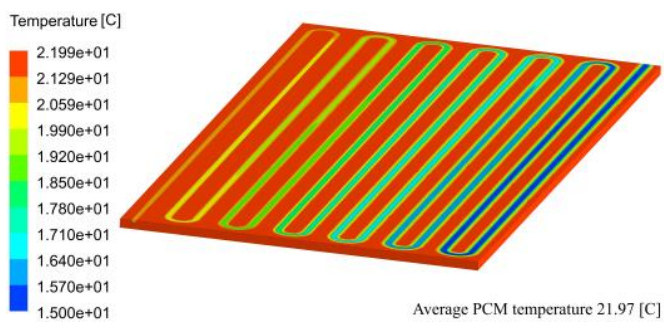

(a)

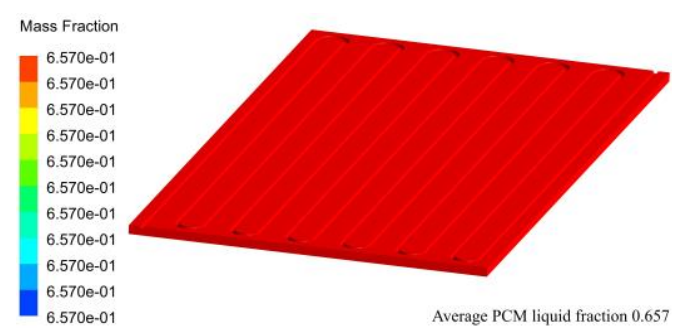

(b)

Fig. 7. Temperature (a) and liquid fraction (b) distribution at the beginning of the night cooling. 


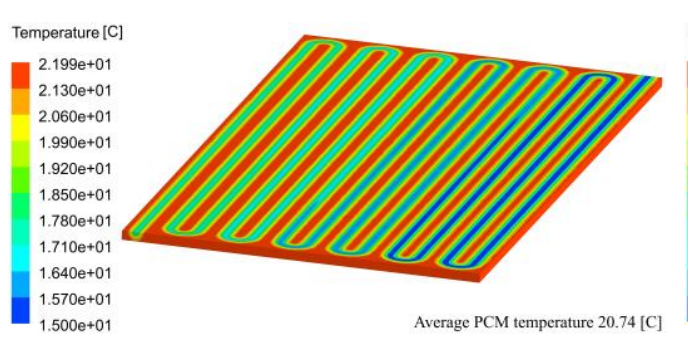

(a)

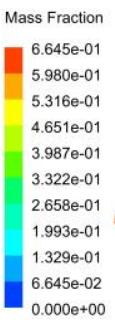

$0.000 e+00$

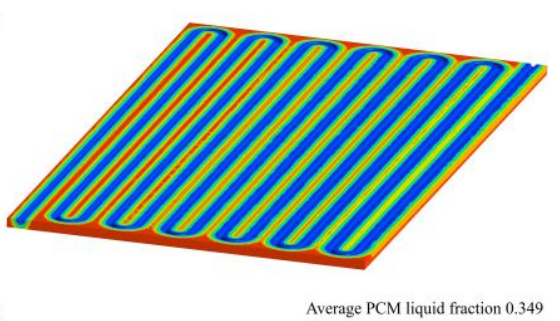

(b)

Fig. 8. Temperature (a) and liquid fraction (b) distribution after $1 \mathrm{~h}$ of the night cooling.

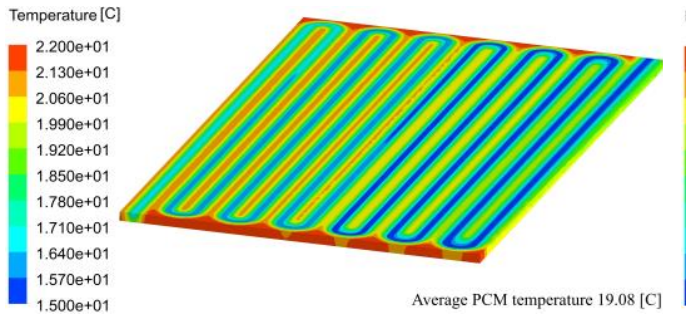

(a)

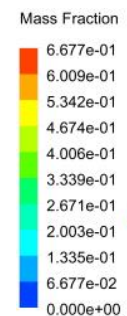

000

Fig. 9. Temperature (a) and liquid fraction (b) distribution after $2.5 \mathrm{~h}$ of the night cooling.

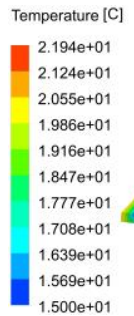

C]

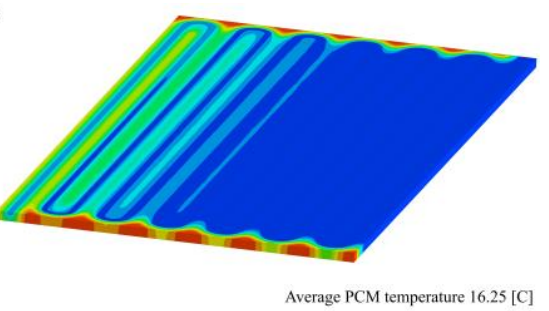

(a)

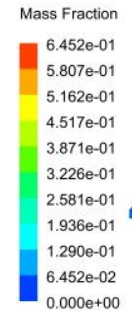

Fig. 10. Temperature (a) and liquid fraction (b) distribution after $3 \mathrm{~h} 46 \mathrm{~min}$ of the night cooling.

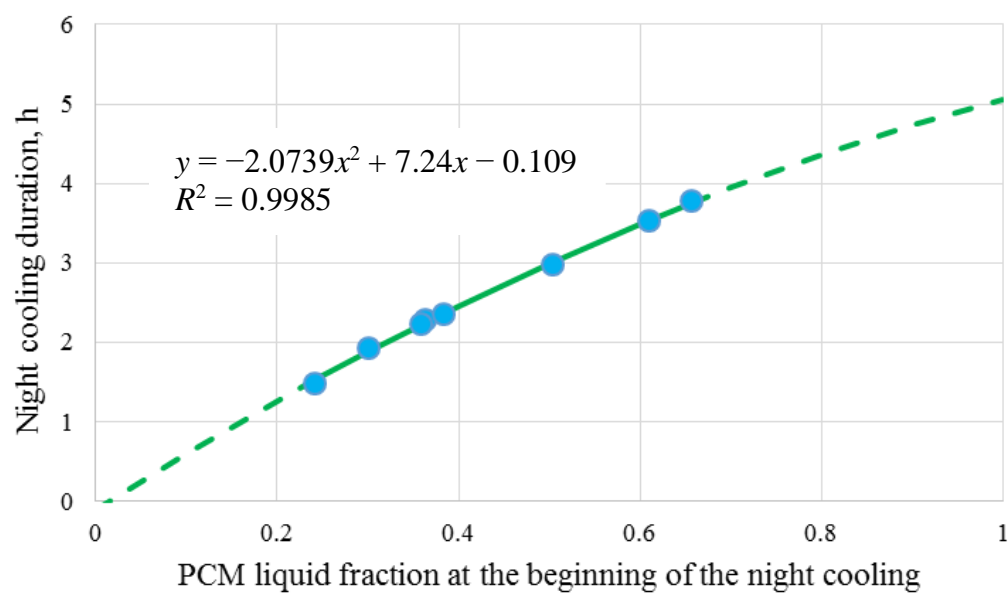

Fig. 11. Night cooling duration dependency on the initial PCM liquid fraction. 


\section{Conclusions}

The objective of the present work was to evaluate the potential of the active PCM incorporated TES system for space cooling in residential buildings. TES system in the form of stand-alone PCM storage units where active control of the thermal storage is achieved by cold water flowing within a capillary pipe system was proposed. For comparison, also the performance of the passive cooling application was investigated. The dynamic thermal simulations were carried out by using the computational fluid dynamics software Ansys Fluent. The results showed that the active cooling application is superior in reducing the indoor air temperature of the studied room compared to the passive one. The main reason is that in the passive application, the PCM suffers from a poor solidification rate during the night not allowing using the full storage capacity of the PCM during the day. The active TES system results in average of $6.8{ }^{\circ} \mathrm{C}$ reduction of indoor air temperatures during the analysis period. In spite of the system's acknowledgeable performance, the maximum indoor temperature rises above the defined thermal comfort level of $28{ }^{\circ} \mathrm{C}$ for a few hours on the hottest days. In the same time, results demonstrate that at the most only $65.7 \%$ of the available $590 \mathrm{Wh} / \mathrm{m}^{2}$ of the present system' s storage capacity has been used which suggests that more than the required amount of the PCM was used. In the ideal case, the entire PCM should be in liquid and solid states at the start and the end of night cooling, respectively. In practice that is almost impossible to obtain, therefore the system should be designed to achieve thermal storage capacity approximately equal to the average heat gains during the daily cycle under minimal energy consumption and operational costs required for the night cooling.

The present configuration of the system requires 27.7 litres of water per hour circulated through one storage unit for the night cooling of the PCM. In total, the whole system circulates $1.5 \mathrm{~m}^{3}$ of water per hour which suggests that closed loop system with heat exchanger should be used. In order to design not only effective but also practical TES system, water circuit system parameters such as storage capacity and heat exchange rate of a water tank as well as capacity and energy consumption of a water pump must also be included in the design optimisation as side constraints.

The main advantage of the proposed concept is that the stand-alone PCM storage units can easily be incorporated into the building interior in required numbers based on the initial thermal conditions of any particular room. This way the optimum performance of the system can be achieved and the entire PCM storage capacity can be used. The results of the numerical design process will be further used to produce prototype modules for laboratory tests.

\section{ACKNOWLEDGEMENT}

The financial support of European Regional Development Fund project Nr.1.1.1.1/16/A/007 "A New Concept for Sustainable and Nearly Zero-Energy Buildings" is acknowledged.

\section{REFERENCES}

[1] The revised Energy Performance of Buildings Directive [Online]. [Accessed 14.02.2019]. Available: https://ec.europa.eu/info/sites/info/files/epbd_factsheet_20180503_dc_v03e_final.pdf

[2] Directive 2010/31/EU of the European Parliament and of the Council of 19 May 2010 on the energy performance of buildings. Official Journal of the European Union 2010:153:13-35.

[3] Directive 2012/27/EU of the European Parliament and of the Council of 25 October 2012 on energy efficiency. Official Journal of the European Union 2012:315:1-56. 
[4] Albatayneh A., Alterman D., Page A., Moghtaderi B. The Significance of Building Design for the Climate. Environmental and Climate Technologies 2018:22(1):165-178. doi:10.2478/rtuect-2018-0011

[5] Bajcinovci B., Jerliu F. Achieving energy efficiency in accordance with bioclimatic architecture principles. Environmental and Climate Technologies 2016:18(1):54-63. doi:10.1515/rtuect-2016-0013

[6] Miezis M., Zvaigznitis K., Stancioff N., Soeftestad L. Climate change and buildings energy efficiency - The key role of residents. Environmental and Climate Technologies 2016:17(1):30-43. doi:10.1515/rtuect-2016-0004

[7] Yang L., Yan H., Lam J. C. Thermal comfort and building energy consumption implications- a review. Applied Energy 2014:115:164-173. doi:10.1016/j.apenergy.2013.10.062

[8] Zhou D., Zhao C. Y., Tian Y. Review on thermal energy storage with phase change materials (PCMs) in building applications. Applied Energy 2012:92:593-605. doi:10.1016/j.apenergy.2011.08.025

[9] Soares N., Costa L. L., Gaspar A. R., Santos P. Review of passive PCM latent heat thermal energy storage systems towards buildings' energy efficiency. Energy and Buildings 2013:59:82-103. doi:10.1016/j.enbuild.2012.12.042

[10] Zeinelabdein R., Omer S., Gan G. Critical review of latent heat storage systems for free cooling in buildings. Renewable and Sustainable Energy Reviews 2018:82(3):2843-2868. doi:10.1016/j.rser.2017.10.046

[11] Du K., Calautit J., Wang Z., Wu Y., Liu H. A review of the applications of phase change materials in cooling, heating and power generation in different temperature ranges. Applied Energy 2018:220:242-273. doi:10.1016/j.apenergy.2018.03.005

[12] Sage-Lauck J. S., Sailor D. J. Evaluation of phase change materials for improving thermal comfort in a superinsulated residential building. Energy and Buildings 2014:79:32-40. doi:10.1016/j.enbuild.2014.04.028

[13] Alam M., Sanjayan J., Zou P. X. W., Ramakrishnan S., Wilson J. A comparative study on the effectiveness of passive and free cooling application methods of phase change materials for energy efficient retrofitting in residential buildings. Procedia Engineering 2017:180:993-1002. doi:10.1016/j.proeng.2017.04.259

[14] Meng E., Yu H., Zhou B. Study of the thermal behavior of the composite phase change material (PCM) room in summer and winter. Applied Thermal Engineering 2017:126:212-225. doi:10.1016/j.applthermaleng.2017.07.110

[15] Wijesuriya S., Brandt M., Tabares-Velasco P. C. Parametric analysis of a residential building with phase change material (PCM)-enhanced drywall, precooling, and variable electric rates in a hot and dry climate. Applied Energy 2018:222:497-514. doi:10.1016/j.apenergy.2018.03.119

[16] Lee K. O., Medina M. A., Sun X. Q., Jin X. Thermal performance of phase change materials (PCM) enhanced cellulose insulation in passive solar residential building walls. Solar Energy 2018:163:113-121. doi:10.1016/j.solener.2018.01.086

[17] Vanaga R., Blumberga A., Freimanis R., Mols T., Blumberga D. Solar façade module for nearly zero energy building. Energy 2018:257:1025-1034. doi:10.1016/j.energy.2018.04.167

[18] Medved S., Arkar C. Correlation between the local climate and the free-cooling potential of latent heat storage. Energy and Buildings 2008:40(4):429-437. doi:10.1016/j.enbuild.2007.03.011

[19] Stritih U., Butala, V. Energy savings in building with a PCM Free cooling system. Journal of Mechanical Engineering 2011:57:125-134. doi:10.5545/sv-jme.2010.066

[20] Weinläder H., Körner W., Strieder B. A ventilated cooling ceiling with integrated latent heat storage - Monitoring results. Energy and Buildings 2014:82:65-72. doi:10.1016/j.enbuild.2014.07.013

[21] Osterman E., Butala V., Stritih U. PCM thermal storage system for 'free' heating and cooling of buildings. Energy and Buildings 2015:106:125-133. doi:10.1016/j.enbuild.2015.04.012

[22] Maccarini A., Hultmark G., Bergsøe N. C., Afshari A. Free cooling potential of a PCM-based heat exchanger coupled with a novel HVAC system for simultaneous heating and cooling of buildings. Sustainable Cities and Society 2018:42:384-395. doi:10.1016/j.scs.2018.06.016

[23] Moreno P., Solé C., Castell A., Cabeza L. F. The use of phase change materials in domestic heat pump and airconditioning systems for short term storage: A review. Renewable and Sustainable Energy Reviews 2014:39:1-13. doi:10.1016/j.rser.2014.07.062

[24] Mazo J., Delgado M., Marin J. M., Zalba B. Modeling a radiant floor system with Phase Change Material (PCM) integrated into a building simulation tool: Analysis of a case study of a floor heating system coupled to a heat pump. Energy and Buildings 2012:47:458-466. doi:10.1016/j.enbuild.2011.12.022

[25] Koschenz M., Lehmann B. Development of a thermally activated ceiling panel with PCM for application in lightweight and retrofitted buildings. Energy and Buildings 2004:36(6):567-578. doi:10.1016/j.enbuild.2004.01.029

[26] Tzivanidis C., Antonopoulos K. A., Kravvaritis E. D. Parametric analysis of space cooling systems based on night ceiling cooling with PCM-embedded piping. International Journal of Energy Research 2012:36(1):18-35. doi:10.1002/er.1777

[27] Zhu N., Ma Z., Wang S. Dynamic characteristics and energy performance of buildings using phase change materials: a review. Energy Conversion and Management 2009:50(12):3169-3181. doi:10.1016/j.enconman.2009.08.019

[28] Waqas A., Ud Din Z. Phase change material (PCM) storage for free cooling of buildings-A review. Renewable and Sustainable Energy Reviews 2013:18:607-625. doi:10.1016/j.rser.2012.10.034

[29] Alizadeh M., Sadrameli S. M. Development of free cooling based ventilation technology for buildings: thermal energy storage (TES) unit, performance enhancement techniques and design considerations - a review. Renewable and Sustainable Energy Reviews 2016:58:619-645. doi:10.1016/j.rser.2015.12.168 
[30] Baetens R., Jelle B., Gustavsen A. Phase change materials for building applications: a state-of-the-art review. Energy and Buildings 2010:42(9):1361-1368. doi:10.1016/j.enbuild.2010.03.026

[31] Sinka M., Korjakins A., Bajare D., Zimele Z., Sahmenko G. Bio-based construction panels for low carbon development. Energy Procedia 2018:147:220-226. doi:10.1016/j.egypro.2018.07.063

[32] Dembovska L., Bajare D., Pundiene I., Vitola L. Effect of Pozzolanic Additives on the Strength Development of High Performance Concrete. Procedia Engineering 2017:172:202-210. doi:10.1016/j.proeng.2017.02.050

[33] RT22HC data Sheet [Online]. [Accessed 14.02.2019]. Available: www.rubitherm.eu/media/products/datasheets/Techdata_-RT22HC_EN_06082018.PDF

[34] Solar calculator [Online]. [Accessed 14.02.2019]. Available: https://meteoexploration.com/products/SolarCalculator.html

[35] Costa M., Buddhi D., Oliva A. Numerical simulation of a latent heat thermal energy storage system with enhanced heat conduction. Energy Conversion and Management 1998:39(3-4):319-330. doi:10.1016/S0196-8904(96)00193-8

[36] Saffari M., Gracia A., Ushak S., Cabeza L. F. Passive cooling of buildings with phase change materials using wholebuilding energy simulation tools: a review. Renewable and Sustainable Energy Reviews 2017:80:1239-1255. $\underline{\text { doi:10.1016/j.rser.2017.05.139 }}$ 